\title{
Germinação de sementes de maracujá-doce (Passiflora alata Curtis): Fases e efeito de reguladores vegetais
}

\author{
Tainara Bortolucci Ferrari ${ }^{1 *}$ \\ Gisela Ferreira ${ }^{2}$ \\ Martha Maria Mischan ${ }^{3}$ \\ Sheila Zambello de Pinho ${ }^{3}$ \\ ${ }^{1}$ PPG em Botânica, Instituto de Biociências, Universidade Estadual Paulista, UNESP \\ Caixa Postal 510, CEP 18618-000, Botucatu - SP, Brasil \\ ${ }^{2}$ Departamento de Botânica, Instituto de Biociências, Universidade Estadual Paulista \\ ${ }^{3}$ Departamento de Bioestaística, Instituto de Biociências, Universidade Estadual Paulista \\ *Autor para correspondência \\ tainara@ibb.unesp.br
}

Submetido em 07/02/2008

Aceito para publicação em 24/04/2008

\section{Resumo}

Objetivou-se caracterizar as fases da germinação e avaliar o efeito de $\mathrm{GA}_{3}$ e $\mathrm{GA}_{4+7}$ associados à fenilmetil-aminopurina na germinação de sementes de Passiflora alata, realizando-se dois experimentos. No primeiro, foram realizados dois tratamentos: sementes submersas em água destilada em béquer e sementes acondicionadas em caixas tipo 'gerbox' entre papel de filtro embebido em água destilada e cinco repetições de 25 sementes. Foram avaliados: grau de umidade e porcentagem de germinação. No segundo, foram realizados seis tratamentos e cinco repetições de 25 sementes para cada regulador. As sementes foram embebidas por $11 \mathrm{~h}$ em soluções a $0,50,100,150,200$ e $250 \mathrm{mg} \mathrm{L}^{-1}$ de $\mathrm{GA}_{3}$ e $\mathrm{GA}_{4+7}$ associados à fenilmetil-aminopurina, semeadas em caixas tipo 'gerbox' preto, sobre papel e levadas à câmara de germinação. Diariamente foram realizadas contagens do número de sementes germinadas e dormentes. Foram calculadas: porcentagem de germinação, porcentagem de sementes dormentes e tempo médio de germinação. Verificou-se que o método de embebição não afetou o padrão de germinação e que ocorreu incremento na porcentagem de germinação e redução do tempo médio de germinação com uso dos reguladores, cujos maiores valores foram obtidos com $250 \mathrm{mg} \mathrm{L}^{-1} \mathrm{de} \mathrm{GA}_{4+7}$ associado à fenilmetil-aminopurina.

Unitermos: embebição, fisiologia da germinação, Passiflora sp., propagação, hormônios e reguladores vegetais

\section{Abstract}

Sweet passion fruit (Passiflora alata Curtis) germination: Phases and effect of plant growth regulator. This work aimed to characterize Passiflora alata germination phases and evaluate the effects of GA 3 and $\mathrm{GA}_{4+7}$, associated with phenylmethylaminepurine, on $P$. alata seed germination. Two experiments were conducted. In the first, two treatments were carried out: seeds submerged in distilled water in a Becker and seeds conditioned in containers on filter paper soaked in distilled water; five replications of 25 seeds were used. The moisture level and the percentage of germination $(\% \mathrm{G})$ were evaluated. In the second, six treatments and five replications of 25 seeds for each regulator were used. The seeds were imbibed in 0, 50, 100, 150, 200 and 250mg.L-1 of GA and 
$\mathrm{GA}_{4+7}$, associated with to phenylmethylaminepurine, for 11 hours. The seeds were sown in black containers and deposited in to the germination chamber. The numbers of germinated and dormant seeds were evaluated daily. The percentage of germination, the percentage of dormant seeds, and the mean germination time (TMG) were estimated. Significant differences in the germination phases between the methods were verified. The germination was affected by the regulators with an increase in the percentage of germination and a reduction in the mean germination time. The highest values were observed with $250 \mathrm{mg} \cdot \mathrm{L}^{-1}$ of $\mathrm{GA}_{4+7}$ plus phenylmethylaminepurine.

Key words: germination physiology, imbibition, Passiflora sp., plant growth regulator, propagation

\section{Introdução}

O maracujazeiro pertence à família Passifloraceae, ordem Passiflorales, encontrando no Brasil as condições ecológicas favoráveis para o seu desenvolvimento e produção. As plantas apresentam propriedades medicinais, são ornamentais e possuem frutos de valor comercial tanto pelo suco como pelo consumo 'in natura' (São José, 1994).

A propagação das Passifloráceas é feita principalmente por meio de sementes e, segundo Pereira e Dias (2000), a germinação de sementes de maracujá é baixa e desuniforme, o que dificulta a formação de mudas de qualidade.

Para melhorar a germinação das sementes é importante que as fases da germinação, envolvendo tratamentos com condicionamento osmótico, préhidratação e emprego de reguladores vegetais, sejam estudadas (Carvalho e Nakagawa, 2000).

A germinação, segundo Bewley e Black (1994) e Castro et al. (2004) é um processo composto por três fases que consistem da embebição (fase I), ativação dos processos metabólicos requeridos para o crescimento do embrião (fase II) e iniciação do crescimento do embrião (fase III).

A duração de cada fase da germinação depende de propriedades inerentes à semente, como a permeabilidade do tegumento, composição química e tamanho das sementes e, também das condições durante a embebição, como temperatura, composição do substrato e presença de reguladores vegetais (Carvalho e Nakagawa, 2000).

Diversos autores, entre eles Ferreira (1998) salientam a necessidade do estudo dos efeitos de reguladores vegetais na germinação de sementes e no processo de formação de mudas de espécies do gênero Passiflora. Esses reguladores estão envolvidos nos processos de crescimento e desenvolvimento de um órgão ou tecido vegetal que podem ser alterados de acordo com as condições fisiológicas da planta (Salisbury e Ross, 1991; Taiz e Zeiger, 2004).

Existem hormônios que atuam como promotores e outros como inibidores no controle do processo germinativo de sementes (Salisbury e Ross, 1991; Takahashi et al., 1991; Taiz e Zeiger, 2004). Hormônios como giberelinas, citocininas e etileno são promotores da germinação, enquanto hormônios como o ácido abscísico é um indutor de dormência. As giberelinas têm ação na síntese de proteínas e RNA específicos na germinação, tanto na quebra da dormência como no controle da hidrólise de reservas, da qual depende o embrião em crescimento (Taiz e Zeiger, 2004).

As citocininas são derivadas da adenina, caracterizada pela habilidade em induzir a divisão celular (Crozier et al., 2001; Taiz e Zeiger, 2004). Na germinação participam no controle de genes, de tradução, da regulação das funções protéicas, da regulação da permeabilidade de membranas e da regulação dos níveis de giberelina (Davies, 1995). Além de exercerem papel na promoção do crescimento da radícula (Horcat e Letham, 1990).

Além do estudo dos efeitos dos reguladores vegetais na germinação de sementes, cabe salientar a necessidade do conhecimento das fases da germinação, inclusive para a determinação de tempos de embebição com os reguladores, conforme reportado por Ferreira (1998) em estudo com P. edulis f. flavicarpa Deg, $P$. giberti, $P$. caerulea e $P$. alata.

Desta forma, este trabalho teve como objetivo caracterizar as fases da germinação em sementes submersas em água e acondicionadas em papel de filtro 
umedecido com água e avaliar o efeito dos reguladores vegetais $\mathrm{GA}_{3}$ e $\mathrm{GA}_{4+7}+$ fenilmetil-aminopurina na germinação de sementes de $P$. alata Curtis.

\section{Material e Métodos}

As sementes de Passiflora alata Curtis foram obtidas de frutos maduros, oriundos de pomar comercial. $\mathrm{O}$ arilo foi retirado manualmente e as sementes colocadas para secar à sombra, sobre papel toalha, por período de sete dias (São José e Nakagawa, 1987). O grau de umidade inicial das sementes foi determinado utilizandose cinco repetições de 25 sementes, pelo método de estufa à $105^{\circ} \mathrm{C}$ por $24 \mathrm{~h}$, de acordo com Brasil (1992).

Para o estudo das fases da germinação, o experimento foi instalado com dois tratamentos em delineamento inteiramente casualizado, com cinco repetições de 25 sementes. No primeiro tratamento (T1) as sementes foram colocadas em béquer de $500 \mathrm{~mL}$ envolvido com papel alumínio, para evitar contato com a luz, onde permaneceram imersas em $200 \mathrm{~mL}$ de água destilada, sob aeração constante, empregando-se bombas de aquário (Ferreira, 1998). No segundo tratamento (T2) as sementes foram mantidas em caixas pretas para germinação ('gerbox' preto) sobre papel de filtro umedecido com água destilada, na quantidade de duas vezes e meia a massa do papel (Brasil, 1992). As sementes foram pesadas em balança analítica com precisão de $0,001 \mathrm{~g}$.

Durante o período das avaliações as sementes foram mantidas em câmaras de germinação, com temperatura alternada de $20^{\circ} \mathrm{C}$, por $16 \mathrm{~h}$ e $30^{\circ} \mathrm{C}$, por $8 \mathrm{~h}$ no escuro conforme sugerido por Ferreira (1998). As avaliações foram realizadas em sala de segurança (com luz verde).

Para a curva de embebição, a cada hora, as sementes foram retiradas de cada tratamento, secas superficialmente com papel toalha e avaliadas, sendo recolocadas no béquer (com $200 \mathrm{~mL}$ de água destilada) ou no 'gerbox'. Este procedimento foi realizado a cada hora, durante um período de $12 \mathrm{~h}$. Após as primeiras $12 \mathrm{~h}$ de avaliação, o procedimento foi repetido a cada $2 \mathrm{~h}$ até se completar $24 \mathrm{~h}$ e posteriormente a cada $8 \mathrm{~h}$ até a emissão da raiz primária.
Para a realização das curvas de germinação, foram estudadas duas variáveis: o grau de umidade da semente a cada hora (a quantidade de água absorvida) e a porcentagem de sementes com emissão de raiz primária no final do experimento, considerando-se $2 \mathrm{~mm}$ de comprimento (Hadas, 1976).

Os dados foram submetidos à análise de regressão, para determinação das fases da germinação. Para ajuste dos modelos estatísticos utilizou-se o modelo de Bradford (1995) para as fases I e II nos dois métodos e para a fase III foi utilizada regressão polinomial de $2^{\circ}$ grau para o método de imersão das sementes em água destilada e regressão polinomial de $3^{\circ}$ grau para o método de sementes acondicionadas em 'gerbox'.

Para o estudo do efeito de $\mathrm{GA}_{3}$ e $\mathrm{GA}_{4+7}$ associados à fenilmetil-aminopurina, instalou-se o segundo experimento. $\mathrm{O}$ delineamento experimental utilizado foi inteiramente casualizado, com cinco repetições de 25 sementes por parcela, seguindo esquema fatorial $2 \mathrm{X} 6$ (reguladores x concentrações), onde a testemunha (sem regulador) foi comum para os dois reguladores.

Os reguladores vegetais utilizados foram $\mathrm{GA}_{3}$ (na forma do produto comercial Pro-Gibb ${ }^{\circledR}$, contendo 10\% de ingrediente ativo) e $\mathrm{GA}_{4+7}$ associado à fenilmetilaminopurina (na forma do produto comercial Promalin ${ }^{\circledR}$, contendo $1,8 \%$ de $\mathrm{GA}_{4+7}$ e $1,8 \%$ de $\mathrm{N}$-(fenilmetil)- $1 \mathrm{H}$ 6-aminopurina). As concentrações empregadas foram $0,50,100,150,200$ e $250 \mathrm{mg} \mathrm{L}^{-1}$ de ingrediente ativo para cada regulador.

As sementes foram imersas em béqueres cujas soluções de reguladores foram oxigenadas com auxílio de bombas de aquário durante $11 \mathrm{~h}$ (tempo determinado no 1 oxperimento).

Com o objetivo de prevenir contaminações as sementes foram previamente submetidas a tratamento com o fungicida dissulfeto de tetrametil-tiuram (thiram) $\left(\right.$ Rodhiauran $^{\circledR}$ ) a $5 \%$ durante $10 \mathrm{~min}$.

A semeadura foi realizada em caixas pretas para germinação $(11,0 \mathrm{~cm} \times 11,0 \mathrm{~cm} \times 3,5 \mathrm{~cm})$, sobre papel de filtro umedecido com água destilada duas vezes e meia a massa do papel. O material tratado foi acondicionado em germinador mantendo-se a temperatura alternada entre $20-30^{\circ} \mathrm{C}(6 \mathrm{~h}-18 \mathrm{~h})$, no escuro. 
As avaliações, realizadas diariamente até 35 dias após a semeadura (DAS), foram constituídas pelas contagens do número de sementes germinadas, ou seja, pelo número daquelas que apresentaram raiz primária com $2 \mathrm{~mm}$ de comprimento (Hadas, 1976). As sementes dormentes (não germinadas e não deterioradas) foram avaliadas no final do experimento (Brasil, 1992). Foram calculadas: porcentagem total de sementes germinadas (PTSG) e porcentagem total de sementes dormentes (PTSD). O tempo médio de germinação (TMG) foi calculado segundo Edmond e Drapala (1958).

As curvas de germinação foram ajustadas pelas curvas de regressão logística, para cada tratamento. A função logística é representada pela equação $\mathrm{y}=a /[1$ $+\exp (-(b+c \mathrm{x}))]$, onde $a$ é o parâmetro denominado assíntota da função, isto é, $a$ é o limite do crescimento de $y$ quando $x$ cresce indefinidamente; o parâmetro $b$ relaciona o crescimento inicial ( $\mathrm{y}$ para $\mathrm{x}=0$ ) com aquele que falta para atingir a assíntota; e o parâmetro $c$ está relacionado com o valor da derivada da função no ponto de inflexão da curva (quanto maior o parâmetro $c$, mais rapidamente o crescimento atinge esse ponto).

A seguir as funções logísticas foram comparadas conforme os tratamentos. O método empregado para essa comparação está descrito em Carvalho (1996). As funções logísticas foram ajustadas utilizando-se o programa SAS (The SAS System. Release 8.2. SAS Institute Inc., Cary, NC, USA. 1999-2001).

Os dados dos parâmetros da função logística, do TMG e da PTSD foram submetidos à análise de variância de acordo com o delineamento inteiramente casualizado para comparação entre os reguladores e a seguir aplicado teste Tukey a 5\% de probabilidade (Pimentel-Gomes, 1990).

\section{Resultados e Discussão}

As figuras 1 e 2 apresentam as fases da germinação e a figura 3 a porcentagem de germinação de sementes de maracujá-doce ( $P$. alata Curtis) submetidas a embebição em becker com água destilada e sobre papel em 'gerbox' preto.

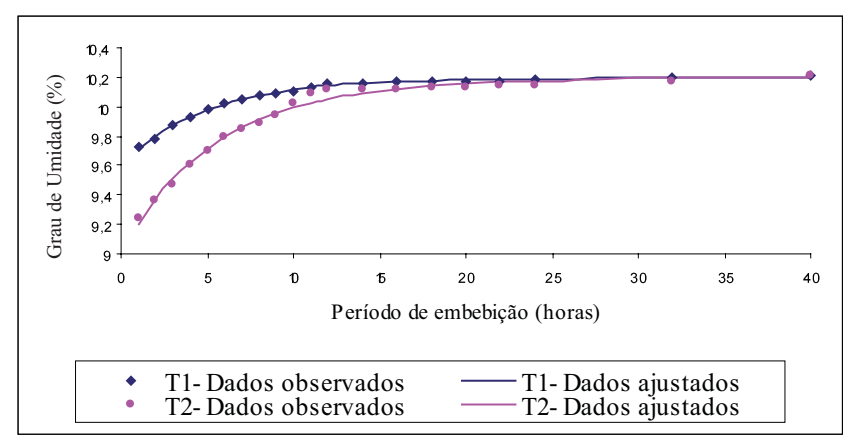

$\mathrm{T} 1=$ Sementes imersas em água destilada: $\mathrm{Y}=(10,179+0,000656 \mathrm{x})$ $-0,580 \exp (-0,207 \mathrm{x})$

$\mathrm{T} 2=$ Sementes acondicionadas em caixas tipo 'gerbox': $\mathrm{Y}=(10,155$ $+0,00123 \mathrm{x})-1,158 \exp (-0,191 \mathrm{x})$

FIGURA 1: Fase I da germinação de sementes de maracujá-doce (Passiflora alata Curtis) submetidas a imersão em água destilada (T1) e acondicionadas em caixas tipo 'gerbox' preto com papel germitest (T2).

Observa-se pelas figuras 1 e 2 que a espécie apresenta comportamento biológico esperado, com as três fases bem definidas, conforme citado por Bewley e Black (1994), com aumento no grau de umidade mais rápido nas primeiras horas (fase I), tendendo à estabilidade com o passar do tempo (fase II) e posterior aumento na velocidade de absorção quando da emissão de raiz primária (fase III).

Em relação à fase I, constatou-se, portanto, que as sementes apresentam permeabilidade à água, o que concorda com Ferreira (1998), que verificou permeabilidade nas sementes de P. edulis f. flavicarpa, $P$. caerulea, $P$. giberti e $P$. alata, em trabalho com sementes também imersas em água. Porém discorda Morley-Bunker (1980), que relata que as sementes de Passifloráceas apresentam dormência devido à impermeabilidade do tegumento, embora o mesmo não especifique as espécies.

Sementes de $P$. alata acondicionadas em 'gerbox' (T2) levaram 10h (0,42 dias) para entrar na fase II, enquanto que sementes submersas em água destilada (T1) levaram $11 \mathrm{~h}$ (0,46 dias) (Figura 1). Embora esta seja a fase mais rápida da germinação, sua duração foi maior do que aquela relatada por Carvalho e Nakagawa (2000) que observaram que a fase I dura entre 1 a $2 \mathrm{~h}$. 


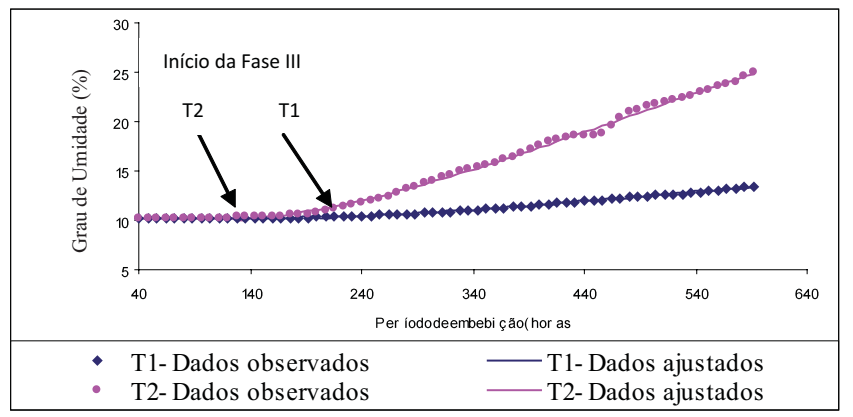

$\mathrm{T} 1=$ Sementes imersas em água destilada $: \mathrm{Y}=(10,179+0,000656 \mathrm{x})$ $-0,580 \exp (-0,207 x)$ quando $\mathrm{x} \geq 200$

$\mathrm{T} 2$ = Sementes acondicionadas em caixas tipo 'gerbox': $\mathrm{Y}=$ $(10,155+0,00123 \mathrm{x})-1,158 \exp (-0,191 \mathrm{x})$ quando $\mathrm{x} \geq 120$

$\mathrm{T} 1=$ Sementes imersas em água destilada: $\mathrm{y}=10,31-0,00493 \mathrm{x}+$ $0,0000262 \mathrm{x}^{2}-0,0000000154 \mathrm{x}^{3}$ quando $\mathrm{x}<200$

$\mathrm{T} 2=$ Sementes acondicionadas em caixas tipo 'gerbox': $\mathrm{y}=10,31-$ $0,00172 \mathrm{x}+0,000122 \mathrm{x}^{2}-0,0000000872 \mathrm{x}^{3}$ quando $\mathrm{x}<120$

FIGURA 2: Fases II e III da germinação de sementes de maracujádoce (Passiflora alata Curtis) submetidas à imersão em água destilada (T1) e acondicionadas em caixas tipo 'gerbox' preto com papel germitest (T2).

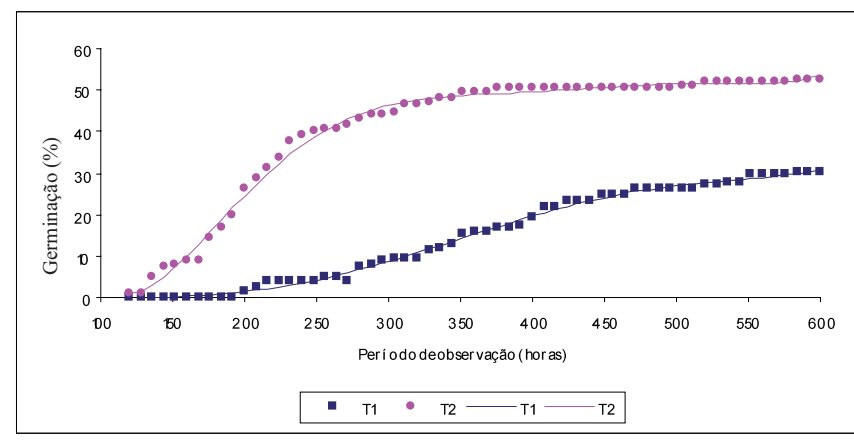

$\mathrm{T} 1-$ Sementes imersas em água destilada $\mathrm{y}=2 \mathrm{E}-11 \mathrm{x}^{5}-4 \mathrm{E}-08 \mathrm{x}^{4}+3 \mathrm{E}-$ $05 \mathrm{x}^{3}-0,0089 \mathrm{x}^{2}+1,3396 \mathrm{x}-77,796 \mathrm{R}^{2}=0,9959$

T2- Sementes acondicionadas em caixas tipo 'gerbox': $y=2 E-13 x^{6}$ $5 \mathrm{E}-10 \mathrm{x}^{5}+5 \mathrm{E}-07 \mathrm{x}^{4}-0,0002 \mathrm{x}^{3}+0,0521 \mathrm{x}^{2}-5,8979 \mathrm{x}+245,28 \mathrm{R}^{2}=0,9939$

FIGURA 3: Porcentagem de germinação de sementes de maracujádoce (Passiflora alata Curtis) submetidas a imersão em água destilada (T1) e acondicionadas em caixas tipo 'gerbox' preto com papel germitest (T2).

As sementes imersas em água destilada no béquer permaneceram na fase II de 11 a $200 \mathrm{~h}(0,46$ a 8,33 dias, respectivamente). Já as sementes que embeberam sob papel permaneceram na fase II de 10 a $120 \mathrm{~h}(0,42$ a 5 dias, respectivamente). O elevado tempo de permanência das sementes imersas em água destilada na fase II, possivelmente é justificado pela anoxia, conforme observado por Coll et al. (2001), o que pode ter reduzido a velocidade dos processos metabólicos.
Na fase II observou-se redução da velocidade de absorção de água conforme citado por Bewley e Black (1994), com aumento lento do grau de umidade, de $10,02 \%$ para $10,31 \%$ ao longo de oito dias nas sementes imersas em água destilada em béquer (T1) e de 9,86\% para $10,31 \%$ ao longo de cinco dias nas sementes que embeberam sobre papel (T2), o que demonstra a não estabilização da entrada de água. A continuidade da entrada de água nesta fase se deve a reduções do potencial osmótico, resultantes do início da quebra de substâncias de reserva em moléculas menores (Castro et al., 2004).

A duração da fase II depende principalmente da temperatura, mas também do potencial hídrico da semente, sendo estendidas sob baixas temperaturas e baixo potencial hídrico (Castro et al., 2004).

A transição da fase II para a fase III da germinação pode ser observada na figura 2. Verifica-se que para a fase III houve diferença entre os métodos empregados e que o tratamento onde as sementes foram mantidas em caixas pretas para germinação apresentou as maiores médias. Para descrever os padrões observados foram ajustados modelos de equações polinomiais quadráticas para sementes imersas em água e cúbicas para sementes acondicionadas em 'gerbox'.

Observa-se, portanto, que a fase III da germinação de sementes de $P$. alata é marcada por aumento no conteúdo de água a partir das $200 \mathrm{~h}$ (8,33 dias) em sementes imersas em água no béquer e, a partir das $120 \mathrm{~h}$ (cinco dias) sobre papel, devido à absorção associada com a iniciação do crescimento do embrião, que culminou com a protrusão de raiz primária, o que significa o final da germinação (Bewley e Black, 1994).

Os resultados referentes à porcentagem de germinação das sementes de $P$. alata submetidas a diferentes métodos de embebição encontram-se na figura 3. Para o método das sementes imersas dentro do béquer houve aumento no tempo necessário para a germinação, sendo que as sementes começaram a emitir raiz primária após $200 \mathrm{~h}$ (8,33 dias). Pode-se observar que no método da embebição sobre papel, a germinação ocorreu mais rapidamente e após $120 \mathrm{~h}$ (cinco dias) do início dos tratamentos houve emissão da raiz primária. 
Cabe acrescentar que em ambos tratamentos a germinação teve início quando o grau de umidade atingiu 10,31\%, confirmando as observações de Carvalho e Nakagawa (2000) de que as sementes necessitam de um mínimo de água para atingirem o nível de hidratação adequado para que inicie a germinação visível.

A partir destes resultados foi realizado o segundo experimento, para avaliar o efeito de $\mathrm{GA}_{3}$ e $\mathrm{GA}_{4+7}+$ fenilmetil-aminopurina na germinação.

Os resultados referentes à porcentagem total de sementes germinadas (PTSG) de Passiflora alata Curtis submetidas a tratamentos com $\mathrm{GA}_{3}$ encontram-se na figura 4 e os resultados das análises de variância na tabela 1 .

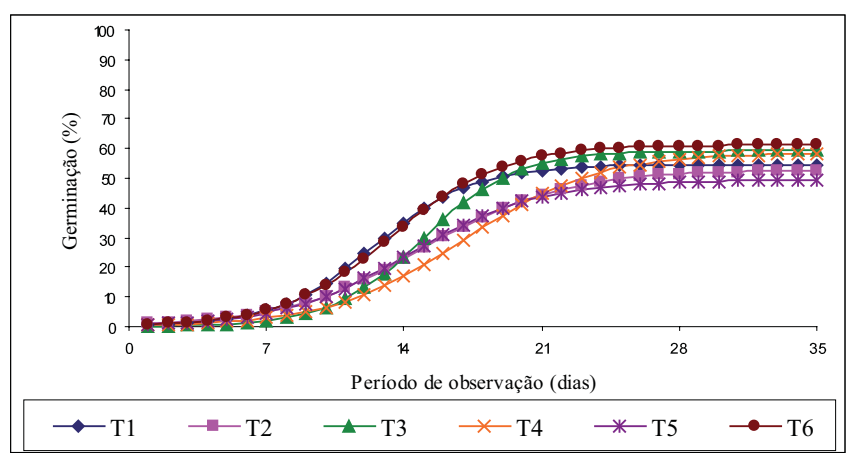

T1- 0 mg L-1 $\mathrm{GA}_{3} \quad \mathrm{~T} 2-50 \mathrm{mg} \mathrm{L}^{-1} \mathrm{GA}_{3} \quad \mathrm{~T} 3-100 \mathrm{mg} \mathrm{L}^{-1} \mathrm{GA}_{3}$ T4- $150 \mathrm{mg} \mathrm{L}^{-1} \mathrm{GA}_{3}$ T5- $200 \mathrm{mg} \mathrm{L}^{-1} \mathrm{GA}_{3}$ T6- $250 \mathrm{mg} \mathrm{L}^{-1} \mathrm{GA}_{3}$

FIGURA 4: Porcentagem média de germinação de sementes de maracujá-doce (Passiflora alata Curtis) tratadas com diferentes concentrações de ácido giberélico $\left(\mathrm{GA}_{3}\right)$, durante o período de 35 dias após a semeadura.

A análise de variância das estimativas dos parâmetros da logística mostrou que o tratamento com $250 \mathrm{mg} \mathrm{L}^{-1}$ de $\mathrm{GA}_{3}$ apresentou maior valor para o parâmetro $a$ (assíntota da função), seguido dos tratamentos 100, 150, 0 (testemunha), 50 e $200 \mathrm{mg} \mathrm{L}^{-1} \mathrm{de} \mathrm{GA}_{3}$ (Tabela 1). Isso significa que as sementes tratadas com a concentração de $250 \mathrm{mg} \mathrm{L}^{-1} \mathrm{de} \mathrm{GA}_{3}$ apresentaram maior porcentagem de germinação ao longo do período estudado, uma vez que $a$ representa o limite do crescimento de y (porcentagem de germinação), seguida por 100 e $150 \mathrm{mg} \mathrm{L}^{-1}$ que foram superiores à testemunha. A testemunha apresentou o maior valor para o parâmetro $c$ (valor da derivada da função no ponto de inflexão da curva) o que significa que esse tratamento atingiu mais rapidamente o ponto de inflexão da curva, ou seja, iniciou a germinação mais rapidamente, porém ao longo do tempo foi superada pela concentração de $250 \mathrm{mg} \mathrm{L}^{-1}$ o que resultou na redução da porcentagem de sementes germinadas no final do experimento (Tabela 1 e Figura 4).

Dessa forma, verifica-se que a embebição das sementes nas soluções contendo 100, 150 e $250 \mathrm{mg} \mathrm{L}^{-1} \mathrm{de}$ $\mathrm{GA}_{3}$ alterou a porcentagem total de germinação (Tabela 1 e Figura 4). O efeito do ácido giberélico no aumento da porcentagem de germinação também foi observado por diversos autores, tais como Ferreira et al. (2001) e Fogaça et al. (2001) variando, porém, as respostas em função das espécies e concentrações utilizadas. Esses resultados demonstram os efeitos da giberelina na promoção da germinação, mais especificamente no controle vários aspectos que vão desde a ativação do crescimento vegetativo do embrião, o enfraquecimento da camada do endosperma que envolve o embrião e restringe seu crescimento, até a mobilização das reservas energéticas do endosperma. A aplicação de giberelinas também estimula a produção de numerosas hidrolases, como a $\alpha$-amilase, conforme relatado em células da camada de aleurona (Taiz e Zeiger 2004).

Assim como neste trabalho, Ferreira (1998) verificou que concentrações baixas de $\mathrm{GA}_{3}$ (menores que $50 \mathrm{mg} \mathrm{L}^{-1}$ ) podem ser insuficientes para aumentar a porcentagem de germinação em sementes $P$. alata e que a imersão das sementes em $100 \mathrm{mg} \mathrm{L}^{-1}$ de $\mathrm{GA}_{3}$ proporcionou aumento nessa variável. Da mesma forma, Rossetto et al. (2000) verificaram que sementes de $P$. alata em contato com substrato umedecido com soluções de 150 e 300 $\mathrm{mg} \mathrm{L}^{-1}$ de ácido giberélico $\left(\mathrm{GA}_{3}\right)$ também apresentaram maior porcentagem de germinação. Além disso, Ferreira et al. (2001) e Fogaça et al. (2001) também observaram que o uso de concentrações mais elevadas de $\mathrm{GA}_{3}$ em sementes do gênero Passiflora promoveu incremento na porcentagem de germinação.

Os resultados referentes ao tempo médio de germinação (TMG) calculado segundo Edmond e Drapala (1958) e porcentagem total de sementes dormentes (PTSD) com o uso do regulador vegetal $\mathrm{GA}_{3}$ encontram-se na tabela 1.

Observa-se que o menor tempo médio de germinação (14,14 dias) foi obtido com 250 $\mathrm{mg} \mathrm{L}^{-1} \mathrm{de} \mathrm{GA}_{3}$ (Tabela 1). Esses resultados demonstram que além da giberelina, 
nesta concentração, promover aumento da porcentagem de germinação $(61,6 \%)$, aumentou a velocidade de germinação o que possivelmente refletirá no tempo para permanência no viveiro.

Esses resultados estão de acordo com Ferreira et al. (2001), quanto ao efeito fisiológico do GA uma vez que constataram que os maiores valores para índice de velocidade de germinação de sementes de $P$. alata foram obtidos com 500mg L-1 de GA e Coneglian et al. (2000) e Rossetto et al. (2000), que utilizaram 150 e 300mg $\mathrm{L}^{-1}$ de $\mathrm{GA}_{3}$ para umedecer o substrato com sementes de maracujá-doce, embora difiram quanto às concentrações empregadas.

A análise de variância mostrou que além do $\mathrm{GA}_{3}$, também foi possível observar efeitos promotores no processo germinativo de sementes de maracujá-doce tratadas com $\mathrm{GA}_{4+7}$ associado à fenilmetil-aminopurina, conforme se verifica na tabela 2 e na figura 5 .

Esses resultados estão de acordo com Ferreira et al. (2001), quanto ao efeito fisiológico do $\mathrm{GA}_{3}$ uma vez que constataram que os maiores valores para índice de velocidade de germinação de sementes de $P$. alata foram obtidos com 500 $\mathrm{mg} \mathrm{L}^{-1}$ de $\mathrm{GA}_{3}$ e Coneglian et al. (2000) e Rossetto et al. (2000), que utilizaram 150 e 300mg $\mathrm{L}^{-1}$ de $\mathrm{GA}_{3}$ para umedecer o substrato com sementes de maracujá-doce, embora difiram quanto às concentrações empregadas.

A análise de variância mostrou que além do $\mathrm{GA}_{3}$, também foi possível observar efeitos promotores no processo germinativo de sementes de maracujá-doce tratadas com $\mathrm{GA}_{4+7}$ associado à fenilmetil-aminopurina, conforme se verifica na tabela 2 e na figura 5.

TABELA 1: Valores dos parâmetros $a, b$ e $c$ da função logística e das abscissas dos pontos de inflexão (P.I.) da curva de germinação e variáveis tempo médio de germinação (TMG) e porcentagem total de sementes dormentes (PTSD) e respectivas equações polinomiais em sementes de Passiflora alata Curtis, conforme tratamento com $\mathrm{GA}_{3}$.

\begin{tabular}{|c|c|c|c|c|c|c|}
\hline Tratamento & $a$ & $\boldsymbol{b}$ & $c$ & $\begin{array}{c}\text { P.I. } \\
(x=-b / c)\end{array}$ & TMG (dias) & PTSD \\
\hline T1- $0 \mathrm{mg} \mathrm{L}^{-1} \mathrm{GA}_{3}$ (Test.) & 55,1498 & $-5,6231$ & 0,4560 & 12,3314 & 14,24902 & 42,4 \\
\hline $\mathrm{T} 2-50 \mathrm{mg} \mathrm{L}^{-1} \mathrm{GA}_{3}$ & 52,8748 & $-4,6088$ & 0,2605 & 17,6921 & 15,90019 & 46,4 \\
\hline T3- $100 \mathrm{mg} \mathrm{L}^{-1} \mathrm{GA}_{3}$ & 59,6179 & $-6,5107$ & 0,4352 & 14,9603 & 16,085 & 39,2 \\
\hline T4- $150 \mathrm{mg} \mathrm{L}^{-1} \mathrm{GA}_{3}$ & 58,1659 & $-5,2989$ & 0,3133 & 16,9132 & 17,23712 & 42,4 \\
\hline T5- $200 \mathrm{mg} \mathrm{L}^{-1} \mathrm{GA}_{3}$ & 49,1243 & $-4,7837$ & 0,3367 & 14,2076 & 15,44203 & 49,6 \\
\hline T6- $250 \mathrm{mg} \mathrm{L}^{-1} \mathrm{GA}_{3}$ & 60,6841 & $-5,6931$ & 0,4141 & 13,7481 & 14,14668 & 38,4 \\
\hline$a, b$ e $c$ & \multicolumn{6}{|c|}{$\mathrm{y}=a /[1+\exp (-(b+c \mathrm{x}))]$} \\
\hline $\mathrm{F}$ & & & & & $46,71 *$ & $0,86 \mathrm{NS}$ \\
\hline TMG & \multicolumn{4}{|c|}{$y=-0,0002 x^{2}+0,04 x+14,214$} & $\mathrm{R}^{2}=0,884$ & \\
\hline
\end{tabular}

TABELA 2: Valores dos parâmetros $a, b$ e $c$ da função logística e das abscissas dos pontos de inflexão (P.I.) da curva de germinação e variáveis tempo médio de germinação (TMG) e porcentagem total de sementes dormentes (PTSD) e respectivas equações polinomiais em sementes de Passiflora alata Curtis, conforme tratamento com $\mathrm{GA}_{4+7}+$ fenilmetil-aminopurina $\left(\mathrm{GA}_{4+7}+\right.$ f.a. $)$.

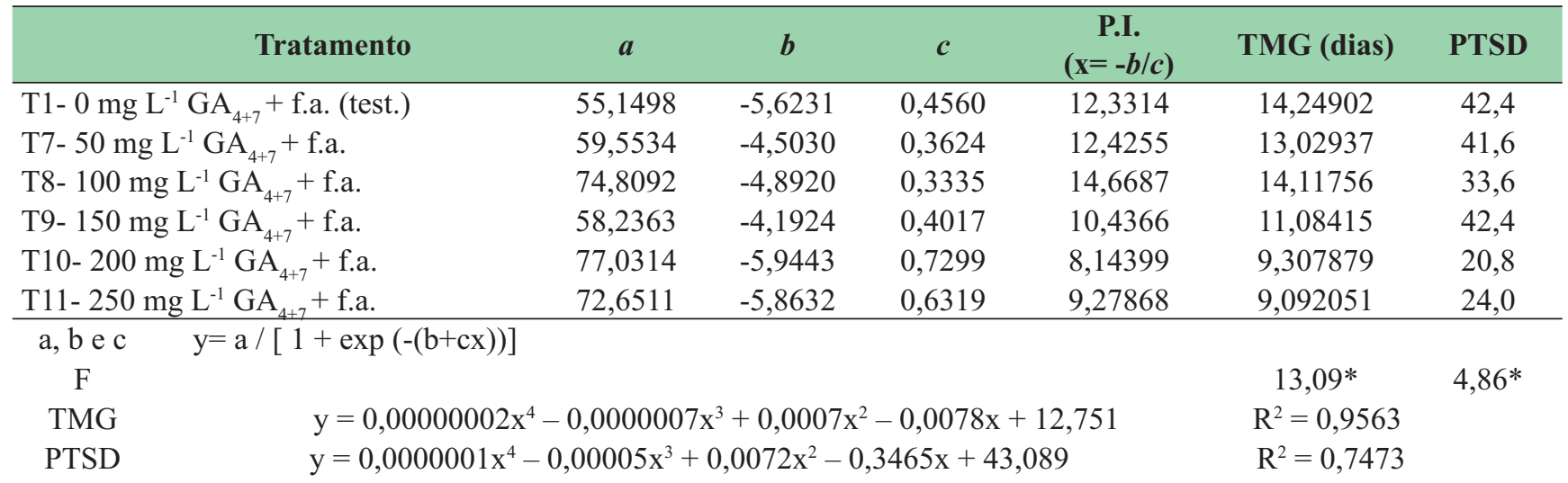




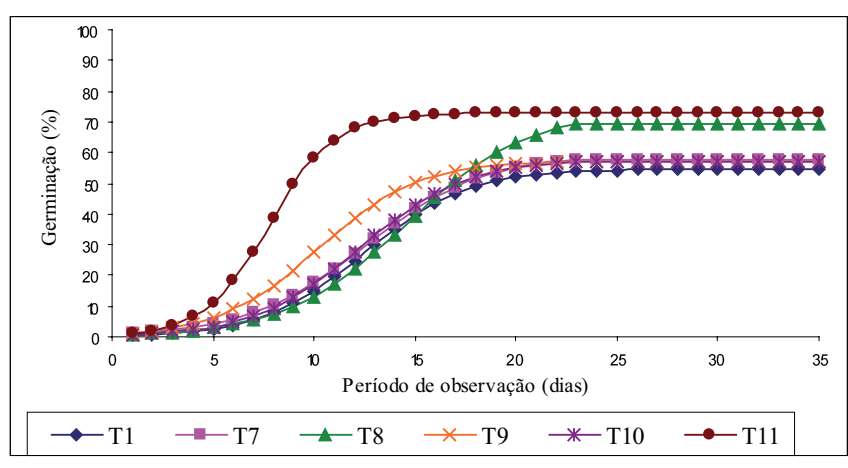

T1- $0 \mathrm{mg} \mathrm{L}^{-1} \mathrm{GA}_{4+7}$ + f.a. $\quad$ T2- $50 \mathrm{mg} \mathrm{L}^{-1} \mathrm{GA}_{4+7}$ + f.a. T3- $100 \mathrm{mg}$ $\mathrm{L}^{-1} \mathrm{GA}_{4+7}$ +f.a. T4- $150 \mathrm{mg} \mathrm{L}^{-1} \mathrm{GA}_{4+7}$ +f.a. T5- $200 \mathrm{mg} \mathrm{L}^{-1} \mathrm{GA}_{4+7}$ + f.a. T6- $250 \mathrm{mg} \mathrm{L}^{-1} \mathrm{GA}_{4+7}+$ f.a.

FIGURA 5: Porcentagem média de germinação de sementes de maracujá-doce (Passiflora alata Curtis) tratadas com diferentes concentrações de $\mathrm{GA}_{4+7}+$ fenilmetilaminopurina $\left(\mathrm{GA}_{4+7}+\right.$ f.a. $)$, durante o período de 35 dias após a semeadura.

O tratamento com $200 \mathrm{mg} \mathrm{L}^{-1} \mathrm{de} \mathrm{GA}_{4+7}+$ fenilmetilaminopurina apresentou maior valor para o parâmetro $a$ (assíntota da função), seguido dos tratamentos 100, 250, 50, 150 e $0 \mathrm{mg} \mathrm{L}^{-1}$ (testemunha) de $\mathrm{GA}_{4+7}+$ fenilmetilaminopurina (Tabela 2 e Figura 5). Isso significa que as sementes tratadas com a concentração de $250 \mathrm{mg} \mathrm{L}^{-1}$ de $\mathrm{GA}_{4+7}+$ fenilmetil-aminopurina apresentaram maior porcentagem de germinação. Esse mesmo tratamento apresentou o maior valor para o parâmetro $c$ (valor da derivada da função no ponto de inflexão da curva) o que indica que ele atingiu mais rapidamente o ponto de inflexão da curva (Tabela 2 e Figura 5).

Os efeitos do $\mathrm{GA}_{4+7}+$ fenilmetil-aminopurina promovendo aumento na porcentagem e velocidade de germinação de sementes de maracujá-doce estão de acordo com Ferreira (1998), que observou aumento na porcentagem de germinação de sementes de $P$. alata tratadas também com mistura de giberelina e citocinina, porém com $100 \mathrm{mg} \mathrm{L}^{-1}$ de $\mathrm{GA}_{3}+60 \mathrm{mg} \mathrm{L}^{-1}$ de $\mathrm{CK}$ (Accel). Comprova-se, portanto, citação de Taiz e Zeiger (2004) de que tanto giberelinas quanto citocininas estão envolvidas na quebra da dormência de sementes de diferentes espécies, provocando com isso, diminuição no tempo médio de germinação.

Os resultados referentes ao tempo médio de germinação (TMG) e à porcentagem total de sementes dormentes (PTSD) com o uso do regulador vegetal $\mathrm{GA}_{4+7}$ + fenilmetil-aminopurina encontram-se na tabela 2 .
Observa-se conjuntamente uma redução na PTSD bem como no TMG nas concentrações 200 e $250 \mathrm{mg} \mathrm{L}^{-1}$ de $\mathrm{GA}_{4+7}+$ fenilmetil-aminopurina.

Os resultados deste experimento estão de acordo com Ferreira (1998) que verificou que as melhores respostas para índice de velocidade de germinação foram obtidas com $100 \mathrm{mg} \mathrm{L}^{-1}$ de $\mathrm{GA}_{3}+60 \mathrm{mg} \mathrm{L}^{-1} \mathrm{de}$ cinetina para $P$. alata e $50 \mathrm{mg} \mathrm{L}^{-1}$ de GA ${ }_{3}$ para $P$. edulis $\mathrm{f}$. flavicarpa demonstrando a eficiência desses reguladores para aumentar o IVG dessas espécies.

Com o objetivo de comparar estatisticamente as respostas obtidas com $\mathrm{GA}_{3} \mathrm{e} \mathrm{GA}_{4+7}+$ fenilmetilaminopurina na germinação ao longo do tempo, estão apresentadas a seguir as análises dos parâmetros $a, b$ e $c$. Desta forma, atenção será dada para a comparação entre os reguladores e não para as concentrações específicas de cada regulador, uma vez que as discussões quanto às concentrações já foram realizadas até o momento.

Os valores obtidos pela análise da interação dos reguladores $\mathrm{GA}_{3}$ e $\mathrm{GA}_{4+7}+$ fenilmetill-aminopurina com as concentrações 50,100,150, 200 e $250 \mathrm{mg} \mathrm{L}^{-1}$ para os parâmetros $a$ (assíntota) e $c$ (valor da derivada da função no ponto de inflexão da curva) encontram-se nas tabelas 3 e 4 . Os valores do parâmetro $b$ (relaciona o crescimento inicial com aquele que falta para atingir a assíntota) não serão apresentados em tabela porque não houve diferença significativa entre os reguladores.

TABELA 3: Valores médios do parâmetro $a$ (assíntota) e valores do teste $\mathrm{F}$ para porcentagem de germinação de sementes de Passiflora alata Curtis submetidas a diferentes concentrações de $\mathrm{GA}_{3}$ e GA $4+7$ fenilmetilaminopurina $\left(\mathrm{GA}_{4+7}+\right.$ f.a. $)$.

\begin{tabular}{lcccccc}
\hline $\begin{array}{c}\text { Reguladores } \\
\text { vegetais }\end{array}$ & \multicolumn{6}{c}{ Concentrações $\left(\mathbf{m g ~ L}^{-1}\right)$} \\
\hline & $\mathbf{0}$ & $\mathbf{5 0}$ & $\mathbf{1 0 0}$ & $\mathbf{1 5 0}$ & $\mathbf{2 0 0}$ & $\mathbf{2 5 0}$ \\
\hline $\mathrm{GA}_{3}$ & $5,1498 \mathrm{a}^{1}$ & $2,8748 \mathrm{a}$ & $9,6179 \mathrm{a}$ & $8,1659 \mathrm{a}$ & $9,1243 \mathrm{~b}$ & $0,6841 \mathrm{~b}$ \\
$\mathrm{GA}_{4+7}+$ f.a. & $5,1498 \mathrm{a}$ & $9,5534 \mathrm{a}$ & $4,8092 \mathrm{a}$ & $8,2363 \mathrm{a}$ & $7,0314 \mathrm{a}$ & $2,6511 \mathrm{a}$ \\
\hline
\end{tabular}

$\mathrm{F}$ dos reguladores $(\mathrm{R}): 38,02 *$

$\mathrm{F}$ das concentrações (C): 7,47*

F RxC: $4,92 *$

${ }^{1}$ Médias seguidas da mesma letra na coluna, comparando-se os reguladores, não diferem entre si, pelo teste Tukey, ao nível de 5\% de probabilidade. 
Pela análise da interação dos reguladores com as concentrações (Tabela 3) verifica-se que para o parâmetro $a$ (assíntota) houve diferença significativa entre os reguladores vegetais nas concentrações de $200 \mathrm{e}$ $250 \mathrm{mg} \mathrm{L}^{-1} \mathrm{e} \mathrm{o} \mathrm{GA}_{4+7}+$ fenilmetil-aminopurina apresentou as maiores médias.

TABELA 4: Valores médios do parâmetro $c$ (valor da derivada da função no ponto de inflexão da curva) e valores do teste $F$ para porcentagem de germinação de sementes de Passiflora alata Curtis submetidas a diferentes concentrações de $\mathrm{GA}_{3}$ e $\mathrm{GA}_{4+7}$ + fenilmetil-aminopurina $\left(\mathrm{GA}_{4+7}+\right.$ f.a. $)$.

\begin{tabular}{|c|c|c|c|c|c|c|}
\hline \multirow{2}{*}{$\begin{array}{c}\text { Reguladores } \\
\text { vegetais }\end{array}$} & \multicolumn{6}{|c|}{ Concentrações $\left(\mathrm{mg} \mathrm{L}^{-1}\right)$} \\
\hline & 0 & 50 & 100 & 150 & 200 & 250 \\
\hline $\mathrm{GA}_{3}$ & $0,4560^{1} \mathrm{a}$ & $0,2605 a$ & $0,4352 \mathrm{a}$ & $0,3133 \mathrm{a}$ & $0,3367 \mathrm{~b}$ & $0,4141 b$ \\
\hline $\mathrm{GA}_{4+7}+$ f.a. & $0,4560 \mathrm{a}$ & $0,3624 a$ & $0,3335 \mathrm{a}$ & $0,4017 \mathrm{a}$ & $0,7299 \mathrm{a}$ & $0,6319 \mathrm{a}$ \\
\hline
\end{tabular}

$\mathrm{F}$ dos reguladores $(\mathrm{R}): 15,47^{*}$

$\mathrm{F}$ das concentrações (C): 6,33*

F RxC: $6,03 *$

${ }^{1}$ Médias seguidas da mesma letra na coluna, comparando-se os reguladores, não diferem entre si, pelo teste Tukey, ao nível de 5\% de probabilidade.

O resultado da análise de interação para o parâmetro $c$ (valor da derivada da função no ponto de inflexão da curva) demonstrou que houve diferença significativa entre os reguladores vegetais também nas concentrações 200 e $250 \mathrm{mg} \mathrm{L}^{-1}$, o que demonstra que as sementes de P. alata tratadas com $\mathrm{GA}_{4+7}+$ fenilmetil-aminopurina apresentaram maior velocidade inicial de germinação.

A análise de interação entre os reguladores $\mathrm{GA}_{4+7}+$ fenilmetil-aminopurina e $\mathrm{GA}_{3}$ com as concentrações 50, $100,150,200$ e $250 \mathrm{mg} \mathrm{L}^{-1}$ para tempo médio de germinação (Edmond e Drapala, 1958) e porcentagem total de sementes dormentes, encontra-se nas tabelas 5 e 6.

O resultado da análise de interação para tempo médio de germinação demonstra que ocorreram interações significativas entre os reguladores, sendo que $\mathrm{GA}_{4+7}+$ fenilmetil-aminopurina proporcionou os menores valores para tempo médio de germinação em todas as concentrações.

Esses resultados evidenciam o efeito do $\mathrm{GA}_{4+7}+$ fenilmetil-aminopurina na redução do tempo médio de germinação em relação ao $\mathrm{GA}_{3}$, uma vez que a germinação de sementes do gênero Passiflora ocorre de forma bastante irregular, podendo este período variar de 10 dias a três meses (Akamine et al., 1972) e neste trabalho observa-se o menor tempo médio com aproximadamente nove dias, com a concentração de $250 \mathrm{mgL}^{-1}$, conforme tabela 5 .

TABELA 5: Valores médios para tempo médio de germinação e valores do teste $\mathrm{F}$ de sementes de Passiflora alata Curtis submetidas a diferentes concentrações de $\mathrm{GA}_{3}$ e $\mathrm{GA}_{4+7}+$ fenilmetil-aminopurina $\left(\mathrm{GA}_{4+7}+\right.$ f.a. $)$.

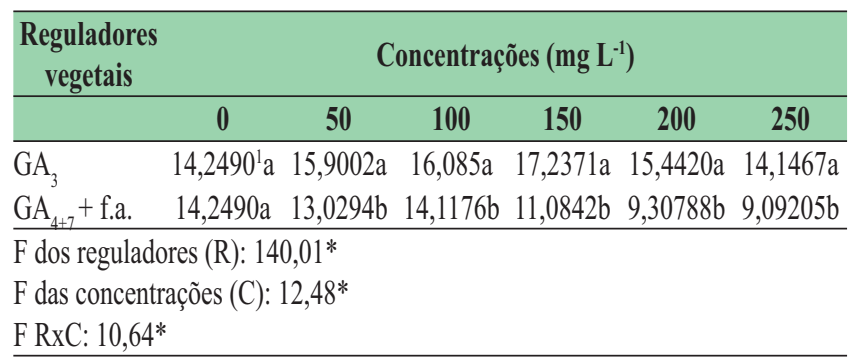

${ }^{1}$ Médias seguidas da mesma letra na coluna, comparando-se os reguladores, não diferem entre si, pelo teste Tukey, ao nível de 5\% de probabilidade.

Diferentemente deste trabalho, onde a germinação das sementes de $P$. alata Curtis iniciou-se com nove dias após a semeadura, Pruthi e Lal (1954) obtiveram início de germinação de sementes de maracujá azedo sem o uso de reguladores vegetais entre 12 e 15 dias após a semeadura, o que se assemelha, portanto à testemunha $\mathrm{e}$ comprova a eficiência do uso de giberelinas associadas à citocinina para acelerar o processo germinativo.

TABELA6: Valores médios para porcentagem de sementes dormentes e valores do teste $\mathrm{F}$ de sementes de Passiflora alata Curtis submetidas a diferentes concentrações de $\mathrm{GA}_{3}$ e $\mathrm{GA}_{4+7}+$ fenilmetil-aminopurina $\left(\mathrm{GA}_{4+7}+\right.$ f.a. $)$.

\begin{tabular}{lcccccc}
\hline $\begin{array}{c}\text { Reguladores } \\
\text { vegetais }\end{array}$ & \multicolumn{6}{c}{ Concentrações $\left(\mathbf{m g ~ L}{ }^{-1}\right)$} \\
\hline & $\mathbf{0}$ & $\mathbf{5 0}$ & $\mathbf{1 0 0}$ & $\mathbf{1 5 0}$ & $\mathbf{2 0 0}$ & $\mathbf{2 5 0}$ \\
\hline $\mathrm{GA}_{3}$ & $42,4^{1} \mathrm{a}$ & $46,4 \mathrm{a}$ & $39,2 \mathrm{a}$ & $42,4 \mathrm{a}$ & $49,6 \mathrm{a}$ & $38,4 \mathrm{a}$ \\
$\mathrm{GA}_{4+7}+$ f.a. & $42,4 \mathrm{a}$ & $41,6 \mathrm{a}$ & $33,6 \mathrm{a}$ & $42,4 \mathrm{a}$ & $20,8 \mathrm{~b}$ & $24,0 \mathrm{~b}$ \\
\hline
\end{tabular}

$\mathrm{F}$ dos reguladores $(\mathrm{R}): 10,43^{*}$

$\mathrm{F}$ das concentrações $(\mathrm{C}): 2,25 \mathrm{NS}$

F RxC: $2,67^{*}$

${ }^{1}$ Médias seguidas da mesma letra na coluna, comparando-se os reguladores, não diferem entre si ao nível de $5 \%$ de probabilidade. 
Com relação a análise de interação entre reguladores e concentrações para porcentagem total de sementes dormentes, pode-se observar diferença significativa entre $\mathrm{GA}_{3}$ e de $\mathrm{GA}_{4+7}+$ fenilmetil-aminopurina nas concentrações de 200 e $250 \mathrm{mg} \mathrm{L}^{-1}$, revelando que as menores médias foram obtidas com $\mathrm{GA}_{4+7}+$ fenilmetilaminopurina.

As aplicações de $\mathrm{GA}_{4+7}+$ fenilmetil-aminopurina, nas concentrações 200 e $250 \mathrm{mg} \mathrm{L}^{-1}$, proporcionaram maiores valores para o incremento do processo germinativo de sementes de $P$. alata Curtis.

\section{Agradecimentos}

À CAPES - Coordenação de Aperfeiçoamento de Pessoal de Nível Superior pela apoio financeiro concedido para realização deste trabalho.

\section{Referências}

Akamine, E. K.; Beaumont, J. H.; Bowers, F. A. I.; Hamilton, R. A.; Nishida, T.; Shermam, G. D.; Shoji, K.; Storey, W. B.; Yee, W. W. J.; Onsdorff, T.; Shaw, T. N. 1972. Passion fruit culture in Hawaii. Cooperative Extension Service Circular, 345: 1-35.

Bewley, J. D.; Black, M. 1994. Seeds: Physiology of development and germination. Plenum Press, New York, USA, 445pp.

Bradford, K. J. 1995. Water relations in seed germination. In: Kigel, J. \& Galili, G. (eds). Seed development and germination. Plenum Press, New York, USA, p.351-396.

Brasil, Ministério da Agricultura. 1992. Regras para análise de sementes. MA/LANARV, Brasília, Brasil, 188pp.

Carvalho, L. R. de. 1996. Métodos para comparação de curvas de crescimento. Tese de Doutorado, Faculdade de Ciências Agronômicas, Universidade Estadual Paulista, Brasil, 172pp.

Carvalho, N. M.; Nakagawa, J. 2000. Sementes: Ciência, tecnologia e produção. FUNEP, Jaboticabal, Brasil, 588pp.

Castro, R. D.; Bradford, K. J.; Hilhorst, H. W. M. 2004. Embebição e reativação do metabolismo. In: Ferreira, A. G. \& Borghetti, F. (eds). Germinação: do básico ao aplicado. Artmed, Porto Alegre, Brasil, p.149-162.

Coll, J. B.; Rodrigo, G. N.; Garcia, B. S.; Tames, R. S. 2001. Fisiologia vegetal. Ediciones Pirâmide S.A., Madrid, Espanha, 566pp.

Coneglian, R. C. C.; Rossetto, C. A. V.; Shimizu, M. K.; Vasconcellos, M. A. S. 2000. Efeitos de métodos de extração e de ácido giberélico na qualidade de sementes de maracujá-doce (Passiflora alata Dryand). Revista Brasileira de Fruticultura, 22: 463-467.
Crozier, A.; Kamiya, K.; Bishop, G.; Yokota, T. 2001. Biosynthesis of hormones and elicitor molecules. In: Buchanan, B. B.; Gruissem, W. \& Russel, L. J. (eds). Biochemestry \& molecular biology of plants. Courier Companies Inc., New York, USA, p.850-929.

Davies, P. J. 1995. Plant hormones: Physiology, biochemistry and molecular biology. Klumer Academic Publishers, London, UK, 833pp.

Edmond, J. B.; Drapalla, W. J. 1958. The effects of temperature, sand and soil, and acetone on germination of okra seed. Proceedings of the American Society for Horticultural Science, 71: 428-443.

Ferreira, G. 1998. Estudo da embebição e do efeito de fitorreguladores na germinação de sementes de Passifloraceas. Tese de Doutorado, Universidade Estadual Paulista, Brasil, 139pp.

Ferreira, G.; Fogaça, L. A.; Moro, E. 2001. Germinação de sementes de Passiflora alata Dryander (maracujá-doce) submetidas a diferentes tempos de embebição e concentrações de ácido giberélico. Revista Brasileira de Fruticultura, 23: 160-163.

Fogaça, L. A.; Ferreira, G.; Bloedorn, M. 2001. Efeito do ácido giberélico $\left(\mathrm{GA}_{3}\right)$ aplicado em sementes de maracujá-doce (Passiflora alata Dryander) para a produção de mudas em diferentes embalagens. Revista Brasileira de Fruticultura, 23: 152-155.

Hadas, A. 1976. Water uptake and germination of leguminous seeds under changing external water potential in osmotic solution. Journal of Experimental of Botany, 27: 480-489.

Horcat, C. H.; Letham, D. S. 1990. Biosynthesis of cytokinin in germination seeds of Zea mays. Journal of Experimental Botany, 41: $1525-1528$.

Morley-Bunker, M. J. S. 1980. Seed coat dormancy in Passiflora species. Annual Journal, 8: 72-84.

Pereira, K. J. C.; Dias, D. C. F. S. 2000. Germinação e vigor de sementes de maracujá-amarelo (Passiflora edulis Sims. f. flavicarpa Deg.) submetidas a diferentes métodos de remoção da mucilagem. Revista Brasileira de Sementes, 22: 288-291.

Pimentel-Gomes, F. 1990. Curso de estatística experimental. Nobel, Piracicaba, Brasil, 468pp.

Pruthi, J. S.; Lal, G. 1954. Germination trials in passion fruit seeds. Indian Journal Horticulture, 11: 138-144.

Rossetto, C. A. V.; Coneglian, R. C. C.; Nakagawa, J.; Shimizu, M. K.; Marin, V. A. 2000. Germinação de sementes de maracujá-doce (Passiflora alata Dryand) em função de tratamento pré-germinativo. Revista Brasileira de Sementes, 22: 247-252.

Salisbury, F. B.; Ross, C. W. 1991. Plant Physiology. Wadsworth, Belmont, USA, 759pp.

São José, A. R. 1994. Maracujá: Produção e mercado. DFZ/ UESB, Vitória da Conquista, Brasil, 255pp.

São José, A. R.; Nakagawa, J. 1987. Efeitos da fermentação e secagem na germinação de sementes de maracujá-amarelo. Semina, 9: $35-43$.

Taiz. L.; Zeiger, E. 2004. Fisiologia Vegetal. Artmed Editora S.A., Porto Alegre, Brasil, 719pp.

Takahashi, N.; Phinney, B. O.; Macmillan, J. 1991. Gibberellins. Springer-Verlag, New York, USA, 426pp. 